\title{
Gaspar de Haro, VII marqués del Carpio: mecenas y colec- cionista de arte
}

\section{Gaspar de Haro, VII Marquis of El Carpio: patron and art collector}

\author{
María Bustillo Merino \\ Universidad de Cantabria \\ Graduada en Geografía e Historia \\ Facultad de Filosofía y Letras. Edificio Interfacultativo \\ Avda. de los Castros, 52. 39005 - Santander \\ maria.bustillo.merino@gmail.com \\ ORCID: https://orcid.org/0000-0003-2643-5072 \\ Fecha de envío: 24/09/2018. Aceptado: 31/10/2018.
}

Referencia: Santander. Estudios de Patrimonio, 1 (2018), pp. 213-232.

ISSN 2605-4450 (ed. impresa) / ISSN 2605-5317 (digital)

Resumen: Este texto revisa el coleccionismo de arte en la segunda mitad del siglo XVII en España e Italia, y analiza a uno de los más ilustres coleccionistas del Barroco español: Gaspar de Haro y Guzmán, VII marqués del Carpio y Heliche (1629-1687). La herencia de un importante linaje, el interés personal y las obligaciones diplomáticas hicieron de su colección y mecenazgo unos de los más importantes de la Historia del Arte de España.

Palabras clave: Coleccionismo; mecenazgo; Monarquía Hispánica, siglo XVII; Gaspar de Haro; marqués del Carpio.

Abstract: This text reviews the collecting in the second half of the seventeenth century in Spain and Italy, and analyzes one of the most distinguished collectors of the Spanish Baroque art: Gaspar de Haro y Guzmán, VII Marquis of El Carpio y Heliche (16291687). The inheritance of a lineage, his personal interest, and his diplomatic responsibilities made Gaspar de Haro one of the most important collections and patronage of the Spanish Art History.

Keywords: Collecting; patronage; Hispanic Monarchy; 17th century; Gaspar de Haro; Marquis of El Carpio.

\section{Gaspar de Haro y Guzmán, vii marqués del Carpio y Heliche}

\subsection{Primeros años y comienzo de su carrera política}

Gaspar de Haro y Guzmán, VII marqués del Carpio (1661-1687), marqués de Heliche (1648-1687) y V conde-duque de Olivares (1661-1687) 
nació en 1629 como hijo primogénito de Luis Méndez de Haro y Guzmán, valido del rey, y de Catalina Fernández de Córdoba. Era además sobrino del conde-duque de Olivares. Gracias a esta eminente ascendencia y a los planes que había preparado Luis para su hijo por ser el primogénito, ocupó desde joven importantes cargos en la corte. El proyecto de encumbramiento del primogénito también afectó al matrimonio. Sus padres acordaron casarlo en 1650 con la hija de los duques de Medinaceli, Antonia María de la Cerda. Cuando ésta murió, el marqués se desposó, en 1671, con Teresa Enríquez de Cabrera, hija del Almirante de Castilla ${ }^{1}$.

Como parte de la carrera política que le había proyectado su padre le cedió alguno de los cargos que ostentaba. El de mayor relieve político fue el de Alcalde del Buen Retiro y "Superintendente" de los festejos reales, que consiguió en 1658. El Superintendente poseía gran importancia pues las celebraciones eran una herramienta vital de la maquinaria política y propagandística de la época. Dentro de los diferentes actos de los que se componían los festejos, destacaba la comedia porque era una útil herramienta para la monarquía ya que se veía beneficiada por aquellas representaciones que expresaban la magnificencia y poder del rey, y mostraban el orden social que debía ser imitado en la vida real ${ }^{2}$.

Los esfuerzos del marqués como Superintendente, ya fuera por complacer a los monarcas o porque buscaba su propio beneficio, sobrepasaban sus funciones al decir de muchos cortesanos. Otra de las críticas sufridas fue la concerniente a los excesivos gastos empleados en las numerosas celebraciones organizadas, sobre todo teniendo en

1 FLÓREZ ASENSIO, María Asunción, “El Marqués de Liche: Alcaide del Buen retiro y "Superintendente" de los Festejos Reales", Anales de Historia del Arte, 20 (2010), p. 146; FRUTOS, Leticia de, El templo de la Fama. Alegoría del Marqués del Carpio. Madrid: Fundación Arte Hispánico, 2009, p. 34; LOPEZ TORRIJOS, Rosa, "Coleccionismo en la época de Velázquez: el marqués de Heliche", en Velázquez y el arte de su tiempo, Madrid, CSIC, 1991, p. 29; FRUTOS, Leticia de, "Tintoretto en las colecciones del marqués del Carpio y del Almirante de Castilla" en Actas del Congreso Internaciona de Jacopo Tintoretto, Madrid, Museo Nacional del Prado, 2009, p. 210.

2 FRUTOS, Leticia de, El templo de la Fama..., pp. 31-45; MARAVALL, José Antonio, La cultura del Barroco: análisis de una estructura histórica, Barcelona, Editorial Ariel, 1983, pp. 471-472; GARCÍA MARTÍN, Pedro y MORA CAÑADA, Adela, "Las fiestas populares en España. Siglos XVI-XVIII" en Il tempo libero. Economiae Società. Secc. XIII-XVIII (Congreso), Florencia, Le Monier, 1995, pp. 260-262. 
cuenta que en aquellos momentos se vivía en una profunda crisis económica. Aunque su carácter impulsivo no fuera el más adecuado, las fuentes revelan que la labor del noble durante este periodo fue esencial en la evolución y devenir de los festejos reales, sobre todo en el teatro cortesano. Más aún en unos años en los que la figura del rey y de la monarquía se habían visto debilitadas y necesitaban recuperar su prestigio y autoridad ${ }^{3}$.

A pesar de los buenos servicios ofrecidos al rey como Superintendente, en 1661, a la muerte de Luis de Haro, Felipe IV prefirió nombrar para ocupar el cargo a Ramiro Núñez de Guzmán, duque de Medina de las Torres. Gaspar de Haro, ahora marqués de El Carpio lo vivió como un duro golpe para sus aspiraciones ya que contaba con sustituir a su padre en los cargos que desempeñaba, pues se consideraba, como hijo que era, el candidato perfecto. Herido en su orgullo, buscó venganza provocando un incendio en el escenario de la corte la noche antes de que fuera estrenada la primera comedia organizada por su sucesor. El suceso dio paso a una investigación que sacó a la luz los desajustes administrativos producidos durante su Superintendencia, sus deudas debido a su impropia forma de vida y la apropiación de funciones que no le correspondían. Finalmente, terminó siendo acusado de intentar atentar contra el rey, lo que le costó dos años de cárcel y ocho de destierro, que le serían perdonados a cambio de ofrecerse voluntario para combatir en Portugal ${ }^{4}$.

Su experiencia en Portugal facilitó que fuera elegido como uno de los representantes de la corona en las negociaciones de paz en 1667. A pesar de que Portugal consiguió la independencia, se alabaron sus buenas formas, sus contactos y su servicio por lo que pudo regresar a Madrid al año siguiente, donde se le devolvieron algunos de los cargos cortesanos que había ejercido con anteriori$\mathrm{dad}^{5}$.

3 FLÓREZ ASENSIO, María Asunción, “El Marqués de Liche..., pp. 165-182; FRUTOS, Leticia de, El templo de la Fama..., p. 46; MARAVALL, José Antoni, La cultura del Barroco..., p. 473.

4 LOPEZ TORRIJOS, Rosa, “Coleccionismo en la época de Velázquez..., p. 28; FLÓREZ ASENSIO, María Asunción, “El Marqués de Liche..., pp. 171-179; FRUTOS, Leticia de, El templo de la Fama..., pp. 61-65.

5 FRUTOS, Leticia de, El templo de la Fama..., pp. 66-67. 


\section{2. Estancia en Italia: Roma y Nápoles}

Durante la segunda mitad del siglo XVII la Santa Sede seguía siendo fundamental tanto en asuntos políticos como religiosos, en gran medida por la ocupación española de la mayor parte de la península italiana. De hecho, era la embajada más cotizada, considerada imprescindible para llegar a ser virrey de Nápoles ${ }^{6}$.

Para poder alcanzar este puesto se consideraba que era prácticamente necesario pertenecer a una gran casa nobiliaria y rica, además de poseer conocimientos políticos y estar informado del tipo de vida aristocrático. Y es que la diplomacia en la Santa Sede era un reflejo más del espíritu barroco, en el que primaban la teatralidad y la apariencia ${ }^{7}$.

El marqués del Carpio fue nombrado embajador de Roma en 1671, aunque no se trasladó definitivamente allí hasta seis años después. Este retraso se debió a varios factores, empezando por las dificultades que para la navegación suponía la plaza africana de Orán. Además, entendió su nuevo cargo como una forma de exilio para alejarlo de la corte, ya fuera por su comportamiento en el pasado o porque era un rival en la carrera hacia el valimiento. De hecho, mantenía la esperanza de poder alcanzar el puesto de favorito del rey, como lo había sido anteriormente su padre, Luis de Haro. Para poder prolongar su estancia en España, alegó una serie de argucias como problemas de salud, pleitos pendientes en el Consejo de Indias o el retraso en el pago de la ayuda de costa y en la preparación de las galeras para su viaje a Roma. Sin embargo, las esperanzas de acceder al valimiento se frustraron al evidenciarse las aspiraciones de Juan José de Austria, de modo que no encontró más impedimentos para retrasar su traslado ${ }^{8}$.

6 FRUTOS, Leticia de, El templo de la Fama..., p. 179; BARRIO GOZALO, Maximiliano. La embajada de España en Roma durante el reinado de Carlos II (1665-1700), Valladolid, Ediciones Universidad de Valladolid, 2013, p. 25; AGUILÓ, María Paz, "Lujo y religiosidad: el regalo diplomático en el siglo XVII" en CABAÑAS BRAVO, Miguel; LÓPEZ-YARTO, Amelia y RINCÓN GARCÍA, Wifredo (coord.), Arte, poder y sociedad en la España de los siglos XV a XX, Madrid, CSIC, 2008, p. 53.

7 AGUILÓ, María Paz, “Lujo y religiosidad..., p. 53; BARRIO GOZALO, Maximiliano, La embajada de España..., pp. 20-21; COLOMER, José Luis (dir.), Arte y diplomacia de la monarquía Hispánica en el siglo XVII, Madrid, Fernando Villaverde, 2003, pp. 20-23; FRUTOS, Leticia de, El templo de la Fama..., p. 180.

8 BARRIO GOZALO, Maximiliano, "El barrio de la embajada de España en Roma en la segunda mitad del siglo XVII", HISPANIA, vol. LXVII, 227 (2007), p. 1008; BA- 
La embajada del marqués del Carpio en Roma se prolongó durante seis años, desde el 13 de marzo de 1676 al 24 de julio de 1682. $\mathrm{Al}$ poco de llegar, se presentó ante el papa Inocencio XI como representante de la Monarquía Hispánica y de los intereses de la Iglesia en nombre de la corona. La imagen que ofreció fue la de un "signore richissimo, e dicono di cervello bizarro", perfecto heredero de dos validos, con un gran interés por las artes ${ }^{9}$, una opinión no alejada de la realidad y sin connotaciones peyorativas.

A priori se esperaba una embajada próspera y en conjunción con el papado, pero los diferentes intereses de ambas partes, sumado a la intervención de los franceses, dañaron las relaciones. Las dificultades comenzaron por las diferencias que el papa mostraba en las relaciones con los franceses y los españoles, inclinándose hacia los primeros. Otro hecho que ahondó en la enemistad fue su intención de adquirir o, como él entendía, recuperar funciones que antes correspondían al embajador y entonces ejercían los nuncios papales. Otro motivo de fricción fueron las levas o reclutamiento de soldados en la Santa Sede. Continuó con esta tradición, aunque Inocencio XI la suspendió en 1676.

Pero no toda la administración del embajador fue problemática pues, durante ese tiempo y a pesar de las confrontaciones, puede afirmarse que consiguió mejorar la imagen que se tenía de los españoles en la Curia romana, así como entre los representantes del resto de naciones europeas. De la misma manera, el marqués sobresalió como embajador por su mecenazgo, su pretensión de devolver a la corona su antiguo prestigio a lo que ayudaron las fiestas organizadas en honor a la monarquía y de las efemérides nacionales ${ }^{10}$. A nivel personal, destacó el protagonismo del embajador en los debates culturales y artísticos. También cuidó los contactos con los más relevantes escultores, arquitectos y pintores del momento, a los que no sólo empleó en la

RRIO GOZALO, Maximiliano, La embajada de España..., pp. 39-40; FRUTOS, Leticia de, El templo de la Fama..., pp. 71-142.

9 FRUTOS, Leticia de, El templo de la Fama..., p. 144.

10 CHECA CREMADES, Fernando. Cortes del Barroco: de Bernini y Velázquez a Luca Giordano, Madrid, Sociedad Estatal para la Acción Cultural Exterior [etc.], 2003, pp. 18-19; BARRIO GOZALO, Maximiliano, "El barrio de la embajada ..., pp. 998-1008; AGUILÓ, María Paz, "Lujo y religiosidad..., p. 53; FRUTOS, Leticia de, El templo de la Fama..., pp. 71-253.; BARRIO GOZALO, Maximiliano, La embajada de España..., pp. 20-78. 
realización de obras artísticas en honor de la monarquía española y Carlos II, como se señala más abajo.

Posiblemente los logros alcanzaron pesaron en Carlos II más que la fuerte personalidad de Gaspar, pues en septiembre de 1682 el monarca le nombró Virrey y Capitán del Reino de Nápoles ${ }^{11}$ donde la nobleza, de enorme poder, mantenía una relación muy estrecha con la nobleza castellana. Desde aquí, el virrey controlaba una parte importante del conjunto de asuntos italianos. En primera instancia, debía velar por los intereses de la corona. Semejante puesto lo convertía en representante e imagen del rey y en un ejemplo de la nobleza y para la nobleza, además de concederle unos extensos territorios bajo su mando. La majestad de la monarquía hispánica iba pareja a la propia grandeza del virrey, situado por encima de los demás cargos del virreinato. El marqués del Carpio no se quedó atrás en este empeño. Uno de los más persuasivos medios utilizados fueron los ceremoniales que se celebraban en la corte virreinal y los eventos públicos en los que utilizó los recursos a su alcance: escenificaciones, emblemas y obras de arte públicas.

Aparte de estas celebraciones, comunes a los demás virreyes de Nápoles, en el caso del marqués del Carpio hay otros dos factores esenciales a destacar. El primero es que se encargó de enmendar y renovar la administración, excesivamente dañada por la corrupción. En segundo lugar, como en el resto de los cargos que ostentó, se ha de destacar el patronato artístico que llevó a cabo como virrey para la corona, es decir, con fines propagandísticos y diplomáticos para ensalzar la figura Carlos II y devolver a la monarquía española el prestigio que había perdido ${ }^{12}$. Sin embargo, como se desarrollará en los apartados siguientes, también aprovechó su posición para favorecer su propia imagen a través de numerosos recursos artísticos y su mecenazgo, lo

11 BARRIO GOZALO, Maximiliano, La embajada de España..., p. 40; CHECA CREMADES, Fernando, “El Marqués de Carpio (1929-1687) y la pintura veneciana del Renacimiento. Negociaciones de Antonio Saurer", Anales de Historia del Arte, 14 (2004), p. 208.

12 CHECA CREMADES, Fernando, El Barroco, Madrid, Istmo, 1982, p. 59; COLOMER, José Luis (dir.), España y Nápoles: coleccionismo y mecenazgo virreinales en el siglo XVII, Madrid, Centro de Estudios Europa Hispánica, 2009, pp. 26-28; HASKELL, Francis, Patronos y pintores: arte y sociedad en la Italia barroca, Madrid, Cátedra, 1984, p. 196; BARRIO GOZALO, Maximiliano, La embajada de España..., p. 40. 
que contribuyó de igual manera a ampliar la magnífica colección que poseía. En definitiva, mejoró el virreinato no sólo a nivel político, sino también cultural y artístico. Ayudó a situar a la ciudad de Nápoles en la vanguardia intelectual de la época.

\section{Coleccionismo y mecenazgo de Gaspar de Haro}

El coleccionismo y mecenazgo cobraron vital importancia durante el Barroco para las clases más altas de la sociedad, pues la colección artística se convirtió en la balanza en la que se pesaba el nivel cultural e intelectual de su poseedor, lo que iba ligado a su prestigio social. En este medio el marqués fue uno de los coleccionistas más importantes del siglo XVII, tanto por la cantidad como por la calidad y variedad de su colección. Su extrovertida personalidad y sus costumbres pródigas se complementaron con un gusto exquisito y un considerable e interés por el arte, lo que le convierte en un gran ejemplo de coleccionista del Barroco $^{13}$.

\section{1. Influencias artísticas y educación}

Las primeras y más importantes influencias proceden de su entorno familiar, de la misma forma que su educación. Dentro de este grupo existieron dos pilares fundamentales, los ya mencionados Luis Méndez de Haro y Guzmán, su padre, y el conde-duque de Olivares, su tío. Ambos referentes consideraban fundamentales en el cursus honorum la utilización de las artes plásticas como herramienta política esencial dentro de las ceremonias y celebraciones, en el protocolo y diplomacia, como garante de prestigio y como demostración de riqueza y poder ${ }^{14}$. No hay que olvidar que parte de la colección de ambos personajes, particulamente la de su padre, le quedaron en herencia, incorporándolas a su colección personal.

El segundo lugar lo ocupó su contexto temporal, social y político: la monarquía de Felipe IV. Una época en la que Velázquez gobernaba

13 LOPEZ TORRIJOS, Rosa, “Coleccionismo en la época de Velázquez..., p. 27; CHECA CREMADES, Fernando, “El Marqués de Carpio..., p. 194.

14 LOPEZ-FANJUL, María, "Las representaciones de don Gaspar de Haro y Guzmán, VII Marqués del Carpio: retratos, alegorías y emblemas", Archivo Español de Arte, vol. LXXXVI, 344 (2013), pp. 291-296; CHECA CREMADES, Fernando, Cortes del Barroco..., p. 21. 
en lo referente a las artes debido a su maestría y profundo conocimiento adquirido en Sevilla, la corte, y en sus viajes por Italia. El cargo de alcalde del Buen Retiro le había permitido acercarse al pintor, además de a otros pintores y escultores que trabajaron en sus producciones teatrales. Le permitió también el poder contemplar de cerca las magníficas colecciones que los monarcas guardaban tanto en el Alcázar como en el palacio del Buen Retiro. Pudo admirar un gran número de pinturas a "la moda", procedentes de la escuela española, pero sobre todo italiana y flamenca. Fue un periodo en el que llegaron jóvenes pintores, como los italianos Agostino Mitelli, Angelo Michele Colonna y Dioniso Mantuano, y en el que destacaron algunos nobles en el patrocinio de las artes. En este ambiente, la corte madrileña evoluciona hacia el auténtico barroco y Gaspar, con ella ${ }^{15}$.

Una vez en Italia, completó su formación como coleccionista y definió y culminó su colección. Durante el periodo romano tuvo la oportunidad de relacionarse con diferentes artistas e intelectuales del mundo del arte como Bernini o Maratta, informándose y pudiendo valorar más acertadamente las obras de arte que adquiría. Su interés se centró, en ese momento, en la pintura veneciana de temas profanos, paisajes y mitología ${ }^{16}$.

\section{2. Mecenas del arte}

El marqués del Carpio ejerció como mecenas del arte desde sus primeros años en la corte española. Ya entonces manifestó predilección por los artistas italianos que residían en la corte y encargó trabajos a Francesco Rizi, Baccio del Bianco o Dionisio Mantuano. Además, como Superintendente de los festejos reales tuvo la oportunidad de conocer a artistas de diversos ámbitos de la cultura, además de patro-

15 LOPEZ TORRIJOS, Rosa, "Coleccionismo en la época de Velázquez..., pp. 2728; CHECA CREMADES, Fernando, "El Marqués de Carpio..., p. 207; CANO DE GARDOQUI, José Luis, Tesoros y colecciones. Orígenes y evolución del coleccionismo artístico, Valladolid, Secretariado de Publicaciones e Intercambio Editorial, 2001, pp. 154-155; MARTÍN GONZALEZ, Juan José, El artista en la sociedad española del siglo XVII, Madrid, Ediciones Cátedra, 1984, pp. 154-160; FRUTOS, Leticia de, "¿Carlos II en clave italiana? Fundamentación del gusto durante el último Austria (1675-1700)" en El siglo de Caravaggio. Obras del Seicento en las colecciones reales, Madrid, Patrimonio Nacional, 2016, p. 80.

16 CHECA CREMADES, Fernando "El Marqués de Carpio..., pp. 194-198. 
cinarles y darles la oportunidad de trabajar para él ${ }^{17}$. Conoció al dramaturgo Calderón de la Barca, a quien contrató obras teatrales como La púrpura de la rosa de 1660, considerada la primera ópera realizada en España, lo que obviamente supuso un importante salto en la evolución del teatro en el país.

En Roma, la labor del embajador como mecenas se fundamentó en la protección de pintores como Carlo Maratta, Luca Giordano, Paolo de Matteis y Pasqualino Veneciano. El embajador visitaba diferentes talleres, entre los que cabe destacar el de Berretoni, Ghezzi, Grimaldi y Bernini que fue su escultor predilecto aparte de que, como es sabido, dominó la vida artística romana durante casi sesenta años. Fallecido Bernini se inclinó por el austriaco Filippo Schor. A este último encargó las carrozas de su hacanea, que evidencia sus altas miras y su refinado gusto, que tanto repercutía en la majestad de la corona como en el lujo y la ostentación propias. Tampoco en Roma se olvidó de los artistas españoles. Allí vivían o visitaban la ciudad numerosos españoles en busca de nuevos conocimientos artísticos y algunos lo conocieron y fueron promovidos por él. También es sabido el intento del marqués por crear una Academia de las Artes en Roma, en 1680, contando con diez artistas de origen español. Conviene recordar el patronazgo que el embajador ejerció con numerosos virtuosos de las letras entre los que destacó Juan Vélez de León, a quién se le atribuye la autoría de diferentes obras poéticas, loas y comedias encargadas por el embajador para ser representadas en las celebraciones reales ${ }^{18}$.

Cuando fue nombrado virrey de Nápoles en 1682 decidió que le acompañase toda una corte de artistas de los que era ya protector en

17 FRUTOS, Leticia de, El templo de la Fama..., p. 43-76; LOPEZ TORRIJOS, Rosa.,"Coleccionismo en la época de Velázquez..., p. 3.

18 MORÁN, Miguel y CHECA, Fernando, El coleccionismo en España. De la cámara de maravillas a la galería de pinturas, Ediciones Cátedra, Madrid, 1985, p. 298; FRUTOS, Leticia de, "Verdad, Mentira, Prudencia y Envidia: cuatro alegorías para el marqués del Carpio en las colecciones reales" en ANSELMI, Alessandra (dir.), I rapporti tra Roma e Madrid nei secoli XVI e XVII: arte e diplomacia e politica, Roma, Gangemi editori, 2015, pp. 649-647; HASKELL, Francis, Patronos y pintores..., pp. 195-196; FRUTOS, Leticia de, "Galerías de ficción. Mercado de arte y de prestigio entre dos príncipes: el VII Marqués del Carpio y el Condestable Colonna", Tiempos Modernos, 14 (2006/2), p. 7; COLOMER, José Luis (dir.), España y Nápoles..., pp. 214-216; DE VECCHI, Pierluigi y CERCHIARI, Elda, I tempi dell'arte. Vol.2, Milán, Bompiani, 2016. p. 348; FRUTOS, Leticia de, El templo de la Fama..., pp. 199-221. 
Roma, como el ya mencionado Filippo Schor. Como virrey, no sólo se preocupó por la pintura, sino también por la arquitectura, encargando la construcción de palacios, iglesias y otros edificios públicos. Todo ello en nombre de la monarquía hispánica. En cuanto a las obras de arte móviles, como la pintura o la escultura, que encargó en nombre o para Carlos II, muchas fueron transportadas a España, entrando a formar parte de la colección real. A nivel personal, el mejor ejemplo que se tiene del estilo de mecenazgo fue el palacio virreinal, que decoró sobre todo con pinturas ${ }^{19}$.

\section{3. Colección artística}

La colección de arte que consiguió formar consta como una de las más importantes de finales del siglo XVII, debido esencialmente a la calidad de las obras, pues no se conformaba solo con adquirir obras de arte, sino que se informaba y estudiaba el arte del presente y del pasado, y sabía qué estaba de moda y quiénes eran los artistas más cotizados.

Gracias a los inventarios ${ }^{20}$ de sus obras de arte, realizados en diferentes momentos de su vida, no sólo se conoce extraordinariamente bien la composición de ésta, sino que se puede dividir en dos partes: la "colección madrileña" y la "colección italiana". Es decir, en primer lugar, estarían las obras que heredó o que compró en Madrid antes de mudarse a Italia, como aquellas de la almoneda de Carlos I de Inglaterra. En segundo lugar, se trataría de las obras que compró durante su estancia en Italia hasta su muerte en 1687.

La primera fuente exhaustiva con la que se cuenta sobre la "colección madrileña" es el inventario de 1651. Gran parte de esta primera colección debía sus orígenes a la herencia familiar, empezando por la de su madre, quien murió en 1647; parte de la biblioteca la heredó de su tío el conde-duque de Olivares; y también consiguió parte de la

19 FRUTOS, Leticia de, “Galerías de ficción..., p. 7; MARTÍN GONZALEZ, Juan José, El artista en la..., p. 151.

20 A partir de las diferentes fuentes utilizadas en la realización del presente trabajo se pueden contabilizar un total de seis inventarios de la obra del Marqués del Carpio: 1651, 1662, 1669, 1677, 1687 ó 1689 y 1690. FRUTOS, Leticia de, “Tintoretto en las colecciones ..., p. 211; PITA ANDRADE, José Manuel, "Los cuadros de Velázquez y Mazo que poseyó el Séptimo Marqués del Carpio", Archivo español de arte, vol.25, 99 (1952), pp. 233-234. 
colección de los Zúñiga. Entre los artistas españoles, la obra más destacada es la Venus del espejo de Velázquez, ya que refleja su prefernecia por la pintura italianizante $y$, a la vez, representa su elevada posición social, pues en este siglo la Inquisición aún tenía un fuerte control sobre la sociedad, a quien vigilaba en salvaguardia de la religión y la moral cristiana. Sólo a unos pocos afortunados, como el monarca y la alta nobleza, se les permitía tener y mostrar esta clase de temas, pues eran considerados los únicos valedores de la moralidad exigible y, además, se les suponía poseedores de los conocimientos necesarios para entender la historia, la mitología y la literatura ${ }^{21}$. En su colección tuvieron un gran peso las obras de la escuela veneciana del siglo XVI, siendo Tintoretto su pintor favorito del que contó con el Lavatorio, los Discípulos de Emaús y un Cristo ante Pilatos ${ }^{22}$.

Como se ha mencionado, la colección real fue una de las fuentes más influyentes en el gusto y colección personal del marqués, que se preocupó por poseer obras de arte que aludieran a la colección del monarca mediante. Así encargó copias de cuadros como el Retrato ecuestre de Felipe IV. El origen de esta imitación no era sólo por motivos de preferencias artísticas, sino que también tenía un fin político, pues le acercaba al rey y a su intento de conseguir su favor.

A la edad de veintidós años el marqués de Heliche ya contaba con una colección de 331 cuadros, entre los que se contabilizaron 39 obras flamencas de Van Dyck, Rubens y Brueghel; 34 cuadros venecianos de Tiziano, Tintoretto, Bassano y Veronés; también piezas de otros italianos y españoles, algunos de segunda fila. Ahora bien, y es muy revelador de la colección, poseía tanto originales como copias. Coleccionaba 59 lienzos de paisajes -10 de ellos con asuntos mitológicos, como las Poesías de Mazo-, 38 bodegones, 44 retratos, 70 de temática religiosa, 27 de carácter propiamente mitológico, 24 composiciones marianas, 21 cuadros de género, 14 florales, 10 de tema bélico y 9 cacerías $^{23}$.

21 FRUTOS, Leticia de, El templo de la Fama..., pp. 75-96; MARTÍN GONZALEZ, Juan José, El artista en la..., p. 173.

22 FRUTOS, Leticia de, "Tintoretto en las colecciones..., p. 210; PITA ANDRADE, José Manuel, “Los cuadros de Velázquez y Mazo..., pp. 226-232; MORÁN, Miguel y CHECA, Fernando, El coleccionismo en España..., p. 297; LOPEZ TORRIJOS, Rosa, “Coleccionismo en la época de Velázquez..., p. 27; HASKELL, Francis, Patronos y pintores..., p. 195; FRUTOS, Leticia de, El templo de la Fama..., p. 73-74.

23 FRUTOS, Leticia de, El templo de la Fama..., pp. 75-91. 
En 1661 murió su padre Luis de Haro, quien le dejó la mayor parte de su colección artística, pues era el primogénito. Buena parte de las obras que había acumulado las vinculó al mayorazgo familiar, a imitación de la monaquía y como habían decidido otros nobles antes que él. La colección paterna constaba de 228 cuadros, con notable presencia de venecianos y flamencos de influencia italianizante. Gaspar se vio obligado a poner en venta algunas de las obras para saldar deudas que el valido había dejado, así como para financiar su viaje a Italia después de conocer su nuevo cargo de embajador en Roma. Sin embargo, se debe destacar que la mayor parte de las piezas que vendidas en almoneda eran copias, pues el nuevo marqués no quiso desprenderse de los originales más valiosos que redundarían en la consideración de su colección y en su prestigio personal ${ }^{24}$.

Siete años después se redactó un inventario de su colección. El nuevo registro se hizo a la muerte de su primera esposa en 1669. Se contabilizaron los bienes de ella y se redactó un listado con los bienes comunes del matrimonio, donde aparecen algunas piezas del marido ${ }^{25}$.

El siguiente inventario de la colección madrileña data de 1677, realizado con motivo de su partida a Roma. La colección presentaba cierto aire cortesano, a imitación de la colección real, aunque se mostraba claramente ya sus preferencias artísticas. Esto dotaba a su colección de una modernidad comparable a muy pocas colecciones de otros nobles de su mismo estatus. Los protagonistas indiscutibles eran los numerosos cuadros que la conformaban, entre los que cabría destacar los de temas profanos y mitológicos.

Instalado en Roma, se informó sobre el panorama artístico y adquirió nuevas pinturas. Este periodo romano ha sido considereado como la cúspide de su actividad coleccionista y de erudición artística. Adquirió obras de escultura clásica que tanto prestigiaba a sus poseedores. Las pudo incluir en su colección gracias a sus privilegiadas relaciones con escultores de la época, posiblemente del círculo de Bernini. Quizás el aprecio por la escultura romana antigua residía en las

24 FRUTOS, Leticia de, El templo de la Fama..., pp. 83-88; CANO DE GARDOQUI, José Luis, Tesoros y colecciones..., pp. 136-157; MORÁN TURINA, Miguel y PORTÚS PÉREZ, Javier, El arte de mirar. La pintura y su público en la España de Velázquez, Madrid, Istmo, 1997, p. 41.

25 FRUTOS, Leticia de, El templo de la Fama..., p. 87. 
escasas oportunidades de compra que existían, sin olvidar la riqueza de los materiales empleados en ella, su antigüedad y su peculiaridad. Una de las mejores oportunidades la tuvo el embajador durante la almoneda del cardenal Camilo Massimi. En esa ocasión adquirió una versión de la fuente de los Cuatro Ríos de Bernini instalada en la Piazza Navona que había sido realizada por este escultor. A imitación del libro impreso con grabados de la colección del arquiduque Leopoldo Guillermo, ordenó dibujar y estampar en un álbum, llamado Álbum Carpio, sus adquisiciones y las esculturas clásicas y modernas obtenidas en Roma. Perseguía su promoción personal y un propósito propagandístico: dar a conocer su colección entre los entendidos y aficionados al arte ${ }^{26}$.

Aparte de la escultura, continuó coleccionando pinturas en Roma. Se mantuvo en su preferencia por la pintura veneciana de la segunda mitad del siglo XVI y particularmente por Tiziano. Añadió obras de los teleri vénetos ${ }^{27}$ y retratos de Tintoretto, Palma el Joven y Veronés. Se han contabilizado hasta 116 pinuras venecianas en su periodo romano. Del foco romano adquirió pinturas de Maratta, su protegido. En los inventarios aparecen citadas 21 obras de este artista, quince de ellas encargadas durante la embajada romana. También adquirió obras de flamencos establecidos en Roma y algunas piezas de Países Bajos: paisajes de Paul Brill y lienzos de Rembrandt, como uno del Dios Pan ${ }^{28}$.

Antes de trasladarse a Nápoles seleccionó las obras que lo acompañarían a su nuevo destino y las que debían enviarse a España. Se quedaron con él las que mayor valor y utilidad tenían, ya fuera a nivel diplomático y político o a nivel personal. Como era habitual entre los virreyes, continuó su labor como mecenas y coleccionista en

26 LOPEZ TORRIJOS, Rosa, "Coleccionismo en la época de Velázquez..., pp. 3435; FRUTOS, Leticia de, "Verdad, Mentira, Prudencia..., pp. 640-650; CHECA CREMADES, Fernando, "El Marqués de Carpio..., pp. 194-208; DE VECCHI, Pierluigi y CERCHIARI, Elda, I tempi dell'arte..., p. 354.

27 Se llama teleri a aquellos pintores venecianos del siglo XVI que utilizaban grandes proporciones de lienzo, el cual colocaban en una pared directamente y lo pintaban al olio, resultando una solución más duradera que los frescos. El término teleri procede de la palabra véneta teler, que en italiano significa telaio (marco). En http:// www.garzantilinguistica.it (consultado el 9 de agosto de 2018).

28 CHECA CREMADES, Fernando, “El Marqués de Carpio..., pp. 195-201; FRUTOS, Leticia de, "Tintoretto en las colecciones ..., p. 210; FRUTOS, Leticia de, "Galerías de ficción..., pp. 13-17. 
Nápoles, no sólo por afición personal, sino también como una de las obligaciones que debía de desempeñar en su nuevo cargo político. En los años del virreinato napolitano pasó su colección de unos 1100 cuadros a 1800. Ingresaron en la colección por primera vez pinturas dee la escuela napolitana, entre los que cabe destacar a Carravaggio, Pier Francesco Mola, Giovani Lanfranco, Salvator Rosa y Aniello Falcone, aunque el artista más representado fue Luca Giordano, del que compró 22 obras $^{29}$.

Después de su muerte, en 1687 se realizó un nuevo inventario de sus bienes en Nápoles en el que se registró un abundante número de lienzos, la mayoría adquiridos durante el virreinato. Entre estas obras pictóricas destacaban las italianas, seguidas por las flamencas y españolas ${ }^{30}$.

\section{4. Empleo del arte como político y diplomático}

En las cortes europeas, la obra de arte podía ser usada como regalo diplomático en busca de favores o como agradecimiento de los mismos entre príncipes y ministros. La corte española, así como sus embajadores y otros cargos en el extranjero, fueron un claro ejemplo de este comportamiento. De hecho, dentro de los gastos financiados a los embajadores y virreyes se contaba con los denominados gastos extraordinarios, en los que se incluía una suma de dinero para ser gastada en este tipo de regalos, pues ayudaban a mover voluntades en las negociaciones diplomáticas. Además, el intercambio de obsequios permitía al emisor la exhibición de su riqueza, pudiendo repartirlos en cierto tipo de actos indicados por la diplomacia del tiempo, como podía ser la visita especial de una personalidad o para reforzar acuerdos políticos. Esta situación ocasionó un mercado interno de obras de arte dentro de las cortes y embajadas que, derivadamente, provocaba una pugna por las mejores piezas ya que su posesión estaba directamente vinculada al prestigio económico, político y social de su dueño ${ }^{31}$.

29 CANO DE GARDOQUI, José Luis, Tesoros y colecciones..., p. 146; HASKELL, Francis, Patronos y pintores..., p. 196; FRUTOS, Leticia de, “¿Carlos II en clave italiana? ..., pp. 81-82.

30 PITA ANDRADE, José Manuel, “Los cuadros de Velázquez y Mazo..., pp. 224234.

31 AGUILÓ, María Paz, “Lujo y religiosidad..., pp. 49-52; BARRIO GOZALO, 
También era un acto común entre la alta nobleza hacer regalos o donaciones al monarca, con el fin de obtener o mantener su favor. Además, permitía el acceso al monarca y la promoción, aparte que podía facilitar la consecución de otras ambiciones personales que pudiera tener un grande de la época. De esta forma se manifestaba la estructura social de la corte, con el monarca a la cabeza, seguido de su red clientelar de nobles. Este comportamiento se evidencia en su biografía. Ya desde sus primeros años en la corte tuvo constancia de la importancia de obsequiar al rey no solo por mera diplomacia, sino también para poder promocionar política y socialmente ${ }^{32}$.

Se sabe que fue uno de los primeros y más importantes coleccionistas de dibujos de la Edad Moderna. Para hacer esta valoración no sólo se tiene en cuenta el número y calidad de su colección, sino también del uso que hizo de ella. No se limitó a recopilar obras de arte, sino que vio en este medio un arma política y propagandística. Tras ser condenado y servir en Portugal, decidió recuperar el favor real y uno de los medios utilizados fue la publicación escrita de sus logros políticos y culturales; acompañados, además, de su retrato. Esta herramienta la continuó usando una vez de vuelta en la corte y durante su periodo en Italia, donde ordenó estampar, comentar y publicar las más significativas obras de su colección, así como los festejos y eventos organizados por él. Complementariamente, estos libros eran usados con fines formativos y pedagógicos, sobre todo los de retratos de "grandes" figuras de la corona y de la corte española, especialmente fuera de la península. Pero por encima de las estampas de sus obras y de las publicaciones, sus retratos jugaron un papel protagonista en sus maniobras políticas ${ }^{33}$.

Su residencia madrileña de San Joaquín o los palacios en los que residió en Italia son otro ejemplo del uso que hacía de su colección. La colocación de las piezas intentaba reflejar su gusto personal, así como la herencia familiar y la influencia o imitación de la corte real. No se ha de olvidar tampoco que como último fin se buscaba conseguir que la

Maximiliano, La embajada de España..., pp. 80-82, FRUTOS, Leticia de, El templo de la Fama..., p. 143; COLOMER, José Luis (dir.), Arte y diplomacia..., pp. 23-25.

32 COLOMER, José Luis (dir.), Arte y diplomacia..., pp. 23-25; FRUTOS, Leticia de, El templo de la Fama..., p. 62.

33 LOPEZ-FANJUL, María, “Las representaciones de don Gaspar..., pp. 292-295; COLOMER, José Luis (dir.), Arte y diplomacia..., pp. 28-29. 
colección fuera un reflejo de su distinción entre la nobleza y, con ello, envidia de sus iguales ${ }^{34}$. Durante su embajada y virreinato promovió obras públicas y festejos, pues era vital que los italianos conocieran a su rey, por lo que encargó la realización de dibujos y esculturas de Carlos II para mostrarlos al público o colocarlos en lugares señalados ${ }^{35}$.

Ha de apuntarse la importante función que desempeñó el teatro en los fines propagandísticos que comentamos. En Madrid, en Roma y Nápoles organizó representaciones teatrales, generalmente como parte del programa de festejos preparados para una celebración concreta, como los cumpleaños reales y, a veces, con fines más personales. También era importante que los representantes de la monarquía hispánica enfatizasen el catolicismo militante que defendían, singularmente en Roma junto al Papa. Así, se ocupó de organizar fiestas religiosas, ya fueran de tradición italiana o española ${ }^{36}$.

En Nápoles, el virrey siguió con sus proyectos de propaganda de la monarquía española, ya que era el álter ego del rey en este territorio italiano. Aprovechó igualmente para obsequiar al monarca para mantener o acrecentar su favor pues, como ya se ha dicho, no había perdido la esperanza de regresar a la corte madrileña. A pesar de lo manifestado, la actuación y mecenazgo del virrey buscó siempre fines personales, compatibilizados con el servicio a la corona e incluso por encima de esta obligación. El número de regalos a al monarca no se puede comparar al de obras que sumó a su colección ${ }^{37}$.

34 FRUTOS, Leticia de, El templo de la Fama..., p. 90; LOPEZ-FANJUL, María, "Las representaciones de don Gaspar...., p. 295; FRUTOS, Leticia de, "Verdad, Mentira, Prudencia..., p. 650.

35 CHENEL PASCUAL, Álvaro, “El arte al servicio del poder y la diplomacia: los retratos escultóricos de Carlos II en Italia" en GUARNIERI CALÒ CARDUCCI, Luigi (ed.), Rumbos del hispanismo en el umbral del Cincuentenario de la AIH, Roma, Bagatto Libri, 2012, vol. II, Historia, pp. 141-150.

36 LOPEZ TORRIJOS, Rosa, “Coleccionismo en la época de Velázquez..., p. 31; COLOMER, José Luis (dir.), España y Nápoles..., p. 30; FRUTOS, Leticia de, "Galerías de ficción..., pp. 2- 3; CHECA CREMADES, Fernando, El Barroco..., pp. 135-143; MARAVALL, Jose Antonio, La cultura del Barroco..., p. 506; MARTÍN GONZALEZ, Juan José, El artista en la..., p. 115; COLOMER, José Luis (dir.), Arte y diplomacia..., pp. 9-26; FRUTOS, Leticia de, El templo de la Fama..., pp. 192-245.

37 COLOMER, José Luis (dir.), España y Nápoles..., p. 31; FRUTOS, Leticia de, “Carlos II en clave italiana? ..., pp. 88-79. 


\section{5. Legado artístico}

El marqués del Carpio murió de forma inesperada en 1687 cuando aún ejercía como virrey. Hasta esa fecha, su labor política y su pasión por el arte le condujeron a acumular una de las mayores y mejores colecciones de arte del Siglo de Oro español. Fue capaz de reunir a lo largo de su vida más de tres mil obras de arte, de las que 1800 eran pinturas. Parte de ellas las vinculó al patrimonio familiar, como había hecho su padre. El resto se repartió entre sus herederos, la mayor parte quedó en manos de su única hija, Catalina. Sin embargo, esta ingente colección se dispersó tras su muerte por las razones mencionadas y porque muchas de las obras fueron sacadas de Nápoles ilegalmente por parte de algunos miembros de su familia. Otras tuvieron que venderse en almoneda en Nápoles, en 1688, para poder saldar las deudas acumuladas; y en nueva almoneda en Madrid en 1690. Como las obras habían sido tasadas en precios muy altos por artistas romanos, no se vendieron en la primera almoneda napolitana y acabaron malvendidas o entregadas directamente como moneda a los acreedores. En Madrid se produjo el caso contrario: las pinturas se tasaron como copias y obtuvieron una baja cotización. La colección se dispersó y el beneficio de los herederos fue limitado ${ }^{38}$.

\section{Bibliografía}

AGUILÓ, María Paz, “Lujo y religiosidad: el regalo diplomático en el siglo XVII" en CABAÑAS BRAVO, Miguel; LÓPEZ-YARTO, Amelia y RINCÓN GARCÍA, Wifredo (coord.), Arte, poder y sociedad en la España de los siglos XV a XX, Madrid, CSIC, 2008, pp. 49-62.

BARRIO GOZALO, Maximiliano, "El barrio de la embajada de España en Roma en la segunda mitad del siglo XVII", Hispania, vol. LXVII, 227 (2007), pp. 993-1024.

BARRIO GOZALO, Maximiliano, La embajada de España en Roma durante el reinado de Carlos II (1665-1700), Valladolid, Ediciones Universidad de Valladolid, 2013.

CANO DE GARDOQUI, José Luis, Tesoros y colecciones. Orígenes y evolución del coleccionismo artístico, Valladolid, Secretariado de Publicaciones e

38 CANO DE GARDOQUI, José Luis, Tesoros y colecciones..., pp. 130-159; PITA ANDRADE, José Manuel, “Los cuadros de Velázquez y Mazo..., p. 224; MARTÍN GONZALEZ, Juan José, El artista en la..., pp. 175-185; FRUTOS, Leticia de, “Galerías de ficción..., pp. 19-20. 
Intercambio Editorial, 2001.

CHECA CREMADES, Fernando, “El Marqués de Carpio (1629-1687) y la pintura veneciana del Renacimiento. Negociaciones de Antonio Saurer", Anales de Historia del Arte, 14 (2004), pp. 193-212.

CHECA CREMADES, Fernando, Cortes del Barroco: de Bernini y Velázquez a Luca Giordano, Madrid, Sociedad Estatal para la Acción Cultural Exterior [etc.], 2003.

CHECA CREMADES, Fernando, El Barroco, Madrid, Istmo, 1982.

CHENEL PASCUAL, Álvaro, "El arte al servicio del poder y la diplomacia: los retratos escultóricos de Carlos II en Italia" en GUARNIERI CALÒ CARDUCCI, Luigi (ed), Rumbos del hispanismo en el umbral del Cincuentenario de la AIH, Roma, Bagatto Libri, 2012, vol. VII, Historia, pp. 140-153.

COLOMER, José Luis (dir.), Arte y diplomacia de la Monarquía Hispánica en el siglo XVII, Madrid, Fernando Villaverde, 2003.

COLOMER, José Luis (dir.), España y Nápoles: coleccionismo y mecenazgo virreinales en el siglo XVII, Madrid, Centro de Estudios Europa Hispánica, 2009.

DE VECCHI, Pierluigi y CERCHIARI, Elda, I tempi dell 'arte. Vol.2, Milán, Bompiani, 2016.

FLÓREZ ASENSIO, María Asunción, "El Marqués de Liche: Alcaide del Buen retiro y "Superintendente" de los Festejos Reales", Anales de Historia del Arte, 20 (2010), pp. 145-182.

FRUTOS, Leticia de, “Galerías de ficción. Mercado de arte y de prestigio entre dos príncipes: el VII Marqués del Carpio y el Condestable Colonna", Tiempos Modernos, 14 (2006/2), pp. 1-20.

FRUTOS, Leticia de, “¿Carlos II en clave italiana? Fundamentación del gusto durante el último Austria (1675-1700)" en El siglo de Caravaggio. Obras del Seicento en las colecciones reales, Madrid, Patrimonio Nacional, 2016, pp. 66-85.

FRUTOS, Leticia de, “Tintoretto en las colecciones del marqués del Carpio y del Almirante de Castilla", Actas del Congreso Internacional de Jacopo Tintoretto, Madrid, Museo Nacional del Prado, 2009, pp. 209-219.

FRUTOS, Leticia de, "Verdad, Mentira, Prudencia y Envidia: cuatro alegorías para el marqués del Carpio en las colecciones reales" en ANSELMI, Alessandra (dir.), I rapporti tra Roma e Madrid nei secoli XVI e XVII: arte e diplomacia e política, Roma, Gangemi editori, 2015, pp. 637-655.

FRUTOS, Leticia de, El templo de la Fama. Alegoría del Marqués del Carpio, Madrid, Fundación Arte Hispánico, 2009.

GARCÍA MARTÍN, Pedro y MORA CAÑADA, Adela, “Las fiestas populares en España. Siglos XVI-XVIII" en Il tempo libero. Economiae Società. 
Secc. XIII-XVIII (Congreso), Florencia, Le Monier, 1995, pp. 257-270.

HASKELL, Francis, Patronos y pintores: arte y sociedad en la Italia barroca, Madrid, Cátedra, 1984.

LOPEZ TORRIJOS, Rosa, "Coleccionismo en la época de Velázquez: el marqués de Heliche" en Velázquez y el arte de su tiempo, Madrid, CSIC, 1991, pp. 27-36.

LOPEZ-FANJUL, María, "Las representaciones de don Gaspar de Haro y Guzmán, VII Marqués del Carpio: retratos, alegorías y emblemas", Archivo Español de Arte, vol. LXXXVI, 344 (2013), pp. 291-310.

MARAVALL, José Antonio, La cultura del Barroco: análisis de una estructura histórica, Barcelona, Editorial Arial, 1983.

MARTÍN GONZALEZ, Juan José, El artista en la sociedad española del siglo XVII, Madrid, Ediciones Cátedra, 1984.

MORÁN TURINA, Miguel y PORTÚS PÉREZ, Javier, El arte de mirar. La pintura y su público en la España de Velázquez, Madrid, Istmo, 1997.

MORÁN, Miguel y CHECA, Fernando, El coleccionismo en España. De la cámara de maravillas a la galería de pinturas, Madrid, Ediciones Cátedra, 1985.

PITA ANDRADE, José Manuel, “Los cuadros de Velázquez y Mazo que poseyó el Séptimo Marqués del Carpio", Archivo español de arte, vol.25, 99 (1952), pp. 223-236. 
